\title{
Surface treatments applied on titanium implants
}

\author{
Sorin Cosmin $\operatorname{COSMA}^{1} *$, Nicolae BALC ${ }^{1}$, Marioara MOLDOVAN ${ }^{2}$ and Cristina Ștefana MIRON-BORZAN ${ }^{1}$ \\ ${ }^{I}$ Technical University of Cluj-Napoca, Department of Manufacturing Engineering, \\ 103-105 B-dul Muncii Street, Cluj-Napoca 400641, Romania \\ ${ }^{2}$ Raluca Ripan Institute for Research in Chemistry, 30 Fantanele Street, Cluj-Napoca, Romania
}

\begin{abstract}
The aim of this systematic review was to identify new methods of surface treatments applied on titanium grafts and their clinical and histological outcomes, including different routes for surface treatments, respectively the results of in vitro or in vivo tests. These surface modifications analysed meet three main requirements: to prevent nonspecific absorption of denatured protein on the surface, to attract native tissue cells or progenitor cells capable of differentiation in an appropriate manner or to facilitate biochemical signals to induce biochemical healing mechanisms. Therefore, cells will recognize these surface modifications and will be influenced in their adhesion behavior, profiling and differentiation. This review summarizes some of the recent developments in coatings for medical field.
\end{abstract}

Keywords: surface treatments, calcium-phosphate, growth factors, collagen, chitosan.

\section{Introduction}

During the last few years, a special attention has been directed to the use of implants with bioactive fixation, where this one is defined by the interfacial bonding of an implant by a tissue. An advantage of this biological fixation is that it forms a bioactive implant-bone interface, strength, equal or greater than that of the bone [1]. Titanium (Ti) and its alloys are used as biomaterials in bone surgery because of the good biocompatibility and mechanical properties. The second reason relates to the $\mathrm{Ti}$ surface which is always covered by a passive oxide layer (a few nanometers) that is responsible for the resistance of the material to corrosion and bioinert behavior in vivo test. This leads to a perfect osseointegration of material [1].

Osseointegration describes the ability of establishing a direct contact between a structural and functional endosseous implant and the bone [2]. The meaning point for all these tries of influence the osseointegration process is given by the interaction between the surface and the tissue (texture), where after implantation appears an uncontrolled absorption occurs on the surface of the implant and in a few seconds is covered by water and ions, followed by absorption to the non-specific plasma proteins. The osseointegration process is influenced by the characteristics of the surface like: composition, surface energy, electrical charge and the potential to transfer this task. Depending on these properties that are determined by the pretreatment implant, absorbed proteins can change conformation during the interaction process.

Although the passive oxide layer formed on the surface of the $\mathrm{Ti}$ confers resistance to corrosion, it doesn't make it bioactive enough for forming a direct connection with the bone. It is known the fact that thickness of the $\mathrm{TiO}_{2}$ increases from 5 to $200 \mathrm{~nm}$ on the surface of the Ti implants after 5 years of implantation [3]. Unmodified $\mathrm{Ti}$ is also suspected by bacterial infection that can lead to the rejection of the implant. These infections can cause devastating complications with high morbidity and treatment costs. A way to reduce bacterial infections on the surface of the implant is to chemically modify the biomaterial surface as to reduce bacterial adhesion, or that bacterial to die upon contact with the surface [4].

Another potential problem is the unpredictable integration of implant into host bone, and the in clinical practice, orthopedic implant osseointegration is often incomplete, resulting over time the risk of losing the implant. To increase the biological tolerance and improve orthopedic implant healing post-implantation, efforts have been made in 
promoting specific interactions between host cells and implanted metallic material. These interactions have been produced by the introduction of proteins of the extracellular matrix and the most commonly used is the peptide containing the amino acid sequence (namely "RGD") [4]. Also, by making implants with porous surfaces that can develop bone tissue with blood vessels for irrigation, the risk of rejection of the implant can be eliminated, phenomenon that occurs relatively frequently in the implants manufactured in a conventional manner. Hydroxyapatite (HA) and tricalcium phosphate (TCP) are the most recruited clinically ceramics to treat bone defects and voids. Biological, stoichiometric $\mathrm{HA}$ of $\mathrm{Ca} / \mathrm{P}$ ratio of 1.67 is highly stable and its very slow degradation is mediated by phagocytosis [5]

The aim of this literature review was to investigate surface treatments applied on $\mathrm{Ti}$ parts. Studies were chosen based on their content and the inclusion criteria were in vitro or in vivo trials. The searches for data published up until December 2014 were undertaken using international databases. Finally, 72 articles were selected and remained for the detailed analysis.

So, for the functioning of medical Ti parts in literature the following surface treatments are proposed: inorganic coatings, coatings with organic biomolecules, composite coatings with $\beta$-TCP and chitosan, biomimetic coating with calciumphosphate and collagen, and acid etched and blasting process. The summary results of these researches will be exposed in this review.

\section{Surface Treatments}

The surface treatment methods for Ti may be: treatments in alkaline or acid environment, by solgel coatings with $\mathrm{TiO}_{2}$, anodic oxidation, etc. Anodic oxidation has become the most used method, because it can easily be used for implants with complex geometric surfaces [6]. In the anodizing process, the Ti piece is immersed in an electrolyte, where an electric current is applied. Thus, a thin layer of $\mathrm{TiO}_{2}$ rough and porous can be obtained. This layer consists enhances in vitro cellular activity of $\mathrm{Ti}$ surface and bone-implant binding properties [7]. Under alkaline treatments aimed primarily, the formation of a surface layer of chemically modified, to improve the ability of apatite formation on the surface of artificial implants to immersion in simulated body fluid (SBF) [8]. Treatments in acid environment modify the implants superficial and increase the thickness of the $\mathrm{TiO}_{2}$ formed naturally. Thus, it improves the adherence and proliferation of cells. Treatment in acid environment could be more intensive if it is performed electrolytic [9, 10]. An alternative to chemical and thermal treatments can be different deposition methods of bioactive coatings on $\mathrm{Ti}$ surface. They aim to chemical bonding of bone adjacent to the implant.

\section{1. Inorganic Coatings}

HA coating on Ti surface is a method frequently used because of its biocompatibility and bioconductivity [11]. The plasma spraying is currently the commercial method of deposition of HA on metal implants [12]. However, long-term stability of the HA coating is problematic due to the presence of a small amount of amorphous with a non-stoichiometric composition and non-uniform $[13,14]$. Therefore, other methods of deposition of HA were developed by international researchers and they will be described below. An electrophoretic deposition technique was used to deposit HA coatings on titanium alloy $\left(\mathrm{Ti}_{6} \mathrm{Al}_{4} \mathrm{~V}\right)$ surface, and then was sintered in vacuum at $800^{\circ} \mathrm{C}$ [15]. It is proved that the surface roughness improves osseointegration of $\mathrm{Ti}$ implants and to increase roughness of implants at nano level to have a surface similar to that of bone, was attempt deposition of nanotubes [16].

A new process was established to produce nanotubes of $\mathrm{TiO}_{2}$, based on the anodized $\mathrm{Ti}$ to improve bioactivity, and to enhance the binding ability of the bone-implant [17]. It is known that HA exhibit bioactivity and also integrates into living tissue by the same mechanism of action in healthy bone remodeling [18]. The nanotubes contribute to increased surface roughness and having a positive effect for subsequent deposition of HA. The structure of the nanotubes serves excellent anchoring of HA by mechanical interlocking of the implant in bone [17].

Preparation of HA deposition of $\mathrm{TiO}_{2}$ nanotubes can be achieved through the following methods: cathodic deposition, electrodeposition and biomimetic deposition. Calcium-phosphate (Ca-P) deposition in nanotubular $\mathrm{TiO}_{2}$ layer is made by a process of electrodeposition where electrolytes 
containing salts. In order to obtain uniform deposition of HA, it was necessary to be treated in an alkaline medium. Submission by a biomimetic method without any surface treatment has been shown to be effective for HA coating of nanotubes of $\mathrm{TiO}_{2}$. Thus, the deposition of HA can be achieved by immersion in SBF, where the calcium and phosphate ions are rapidly deposited on the nanotubular film [17].

W. Medeiros et al. [19] studied a biomimetic process of precipitation porous $\mathrm{Ti}$ implants to be bioactive. The study reveals that Ti samples with interconnected open and closed pores were prepared by powder metallurgy and then immersed in SBF at $37^{\circ} \mathrm{C}$ for 2-28 days. Analysis of SEM images, shows that deposition of $\mathrm{Ca}-\mathrm{P}$ to $\mathrm{Ti}$ surfaces takes place without any pretreatment, thus can improve the bioactivity of parts made of $\mathrm{Ti}$ alloy. The study concluded that the immersion of samples in SBF promote the nucleation and growth of crystals of $\mathrm{Ca}-\mathrm{P}$, for example HA on the surface of the material.

\section{2. Coatings with organic biomolecules}

Bioactive molecules can be immobilized on the surface of the Ti to enhance the regeneration of the bone implant interface. Compared with the filing of the above inorganic phosphate, changes of surface biomolecules using pure organic components of bone tissue are in order to influence the response [20]. So far there are used four approaches to deposit organic molecules: immobilization of extracellular matrix protein or peptide sequences as modulators of cell adhesion to bone [21], deposition of the growth factors to the onset of new bone formation, immobilization of DNA (deoxyribonucleic acid) structural reinforcement and $\mathrm{Ti}$ surface modification of enzymes to improve bone mineralization [22].

Growth factors are proteins that serve as a cell signaling agents, and are secreted by cells that must meet a specific action. They promote replication, differentiation, protein synthesis and/or migration of a suitable cell type [20]. Once a growth factor binds to a receptor on a cell, it induces the intracellular signaling system that produces a biological response. Thus, the release of growth factors from the surface of the implant may increase the bone tissue osteoblast activity, promoting bone regeneration. Regeneration of bone around the implant can be increased by the immobilization of growth factors such as bone-forming proteins (BMP), transforming growth factor type $\beta$ (TGF- $\beta$ ), fibroblast growth factors (FGF) on the surface of Ti. A common osteogenic growth factors used in the medical field are TGF- $\beta$ superfamily, including BMP family [2325].

Improving osteoconductivity of $\mathrm{Ca}-\mathrm{P}$ coatings can be produced by the addition of bone growth factors. Regeneration of bone around the implant coated with $\mathrm{Ca}-\mathrm{P}$ can be greatly enhanced by immobilizing the growth factor BMP-2 and TGF- $\beta$ on the surface of the implant. Immobilization of growth factors leads to inorganic Ca-P delay the transport of growth factor and making its high stability [20]. Y. Liu has been used Ca-P coatings on Ti surface for transport the growth factors such as BMP-2 [26]. Ca-P coating involves the nucleation and growth of mineral crystals of the bone, following a pre-treatment of the implant by dipping it into a supersaturated solution of $\mathrm{Ca}-\mathrm{P}$ under physiological conditions of temperature $\left(37^{\circ} \mathrm{C}\right)$ and $\mathrm{pH}$ (7.4). The layer of Ca-P formed and then as a transport system incorporating varied amounts of the growth factor BMP-2 (1-3 $\mu \mathrm{g} /$ implant). For in vitro tests, potential osteogenic growth factor incorporated BMP-2 was evaluated by monitoring alkaline phosphatase activity of bone marrow stromal cells of rats. Thus, the potential of the osteogenic growth factor BMP-2 is not only retained but it is enhanced by its incorporation of Ca-P layer, perhaps by virtue of a localized concentration effect. So, immobilization of growth factors on the surface of pre-coated $\mathrm{Ti}$ implants with collagen, or $\mathrm{Ca}-\mathrm{P}$ were found to be more effective in inducing the formation of the bone than the binding of the growth factor directly to the surface of untreated $\mathrm{Ti}$ [20].

\section{3. Composite coatings with $\beta$-TCP and chitosan}

Medical devices and implants could be a main source for bacterial adhesion and can create different complications in surgery field $[27,28]$. Some of $\mathrm{Ti}$ implants do not prevent these complications and an alternative could be a bioactive coating with antiseptic properties like Chitosan (CS). CS is a biological, biodegradable and nontoxic polymer [30, 31 ] and it has been shown that it can increase the growth and attachment of cells [32, 33]. The antibacterial properties are provided by the positive charge of the amino groups along the biopolymer chain $[34,35]$. 
P. Renoud et. al [36] investigated the functioning of titanium with CS via a silanation. The surface chemistry and mechanical properties of the samples were analyzed. The results showed that the CS proves to be a good solution for coating the $\mathrm{Ti}$, the obtained structure has good mechanical properties and the antibacterial properties are maintained. Also, the coated material is non-cytotoxic for fibroblasts and it is more biocompatible than $\mathrm{Ti}$. The researchers concluded that this method of covalent coating provides a biocompatible material with improved bioactive properties [36].

Also, CS coating on the $\mathrm{Ti}$ alloy implant promotes the antioxidant effect and supportive function on osteoblastic biological behavior under diabetic conditions, which was further confirmed by improved osseointegration in diabetic sheep [37]. This research provides deep insight into the mechanisms underlying diabetes-induced impaired osseointegration targeting at the bone-implant interface. The anti-oxidative property of CS could be an alternative therapeutic strategy for accelerating the integration of $\mathrm{Ti}$ and reducing implant failure in diabetic patients [37].

\section{4. Biomimetic coating with calcium-phosphate and collagen}

Natural polymer like collagen has the ability to support the cell growth in most tissues. It enjoys several advantages including versatility and processability that enables imparting the desired morphology like porosity (different range of pore sizes and shapes) and suitable mechanical response. Physical-chemical properties of polymer matrices could be modified and the mechanical characteristics and degradation rate can be suitably tailored by varying the chemical composition. The incorporation of additive chemical functionalities is therefore required in order to improve their chemical bioactivation [38-40].

A composite coating consisting of collagen and Ca-P mineral is believed to be bioactive and can enhance the growth of the bone and fixation of the implant of Ti. Since collagen is the main organic component of the extracellular matrix, it induces a positive effect on cell adhesion, proliferation, and differentiation of many cells in culture. Also, collagen provides a high biodegradability and excellent biocompatibility in vivo test. Xia Z. et al. [41] used to conduct research three solutions of SBF with different contents of collagen and the $\mathrm{Ti}$ samples were soaked in these SBF modified solutions at $40^{\circ} \mathrm{C}$ for 24 hours. Following characterization of composite samples coated with collagen/apatite it could be concluded that osteoblastic cell proliferation was significantly higher compared to pure apatite deposit only [41]. For long-term primary stability of an implant with bioactive coating, the adhesion resistance is very important.

a)

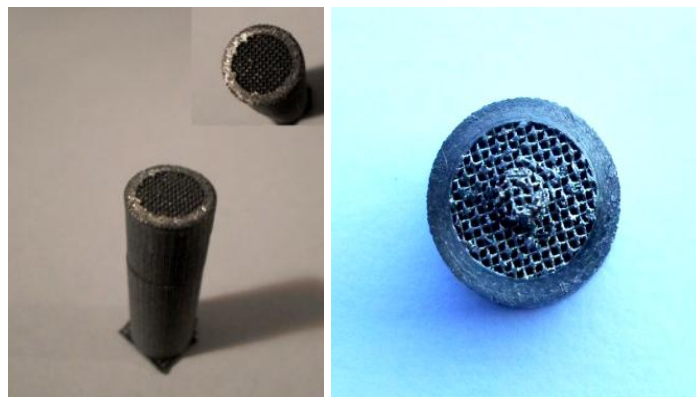

b)

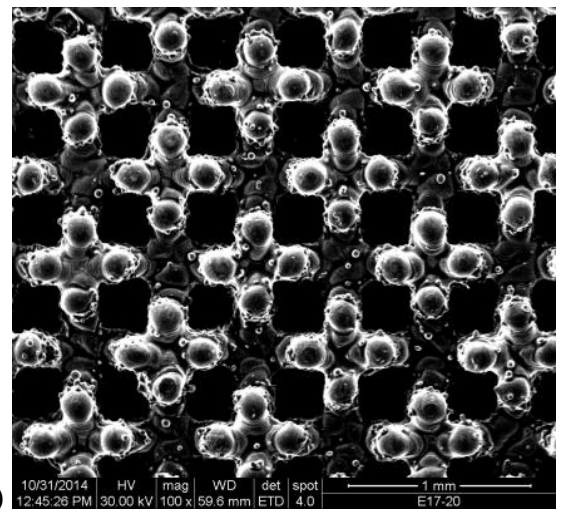

Fig. 1. Endosseous experimental implants manufactured by AM process from $\mathrm{Ti}$, a) Cylindrical implant with $56 \%$ porosity and 2 zones: a compact one with $2.5 \mathrm{~mm}$ thickness similar to cortical bone and a macroporous area made from lattice structure with interconnected pores like trabercular bone;

b) SEM imagine with macroporous structure (lattice), 100x magnification

The bonding strength test shows that the deposit doesn't have a high resistance and produce invoices. This surface treatment can be applied on implants with lattice zone [42] and the adhesive strength between bone and implant in this area will be avoided. Figure 1 shows an example made by Additive Manufacturing (AM) process from $\mathrm{Ti}$ 
powder, similar to the human bone with a compact zone like cortical bone and a macroporous area like trabercular bone, which could be biomimetic coated with $\mathrm{Ca}-\mathrm{P}$ and other natural or synthetic polymers, especially in this interconnected lattice area. These samples presented in Fig. 1 were developed by authors of this review for future bioactive coatings.

W. At. et al. [43] published a complex study about the effect of UV on bioactivity of Ti implants. The researchers cultured rat bone marrow-derived osteoblastic cells on the Ti implants (new and old Titanium disks, Titanium disks treated with UVA, Titanium disks treated with UVC) and studied possible changes of the bioactivity for $\mathrm{Ti}$ surfaces during their aging. They also investigated the effect of UV light treatment on these surfaces [43]. They concluded that UVC treatment of the aged surface increased its cell attachment capacity to a level $50 \%$ higher than the new surfaces, whereas UVA treatment had no effect [43].

Biomimetic treatments in combination with bioactive bulk inclusions may assure a uniform bioactivation of different substrates by promoting an efficient nucleation and growth of bone-like crystals for bone regeneration $[38,44]$. It was clearly shown in many scientific papers that Ca-P coating accelerates bone formation around the implant [38] and promotes bone healing and apposition, leading to the rapid biological fixation of implants.

\subsection{Acid etched and blasting process}

Based on promising experimental data, clinical trials using implants with sandblasted and acidetched (SLA) surfaces were initiated to test the new Ti surfaces in patients. These trials showed that healing periods with the new surfaces were shorter than the healing periods of 3-6 months that had been the standard in clinical practice for almost three decades [45-54]. SLA provides both a micro roughness and waviness that seems to enhance bone contact with the implant surface. The Ti surface was first sandblasted with large particles creating a grossly rough surface followed by acid etching, forming a micro rough surface with micro pits between 1-4 $\mu \mathrm{m}$ [55-57]. Similar rough surfaces developed by the authors of this review can be seen in Fig. 2. It has also been shown in vivo test made on rabbits that implants with this macro-textured surface ensured better endosseous integration and improve the implant primary stability $[55,57]$.

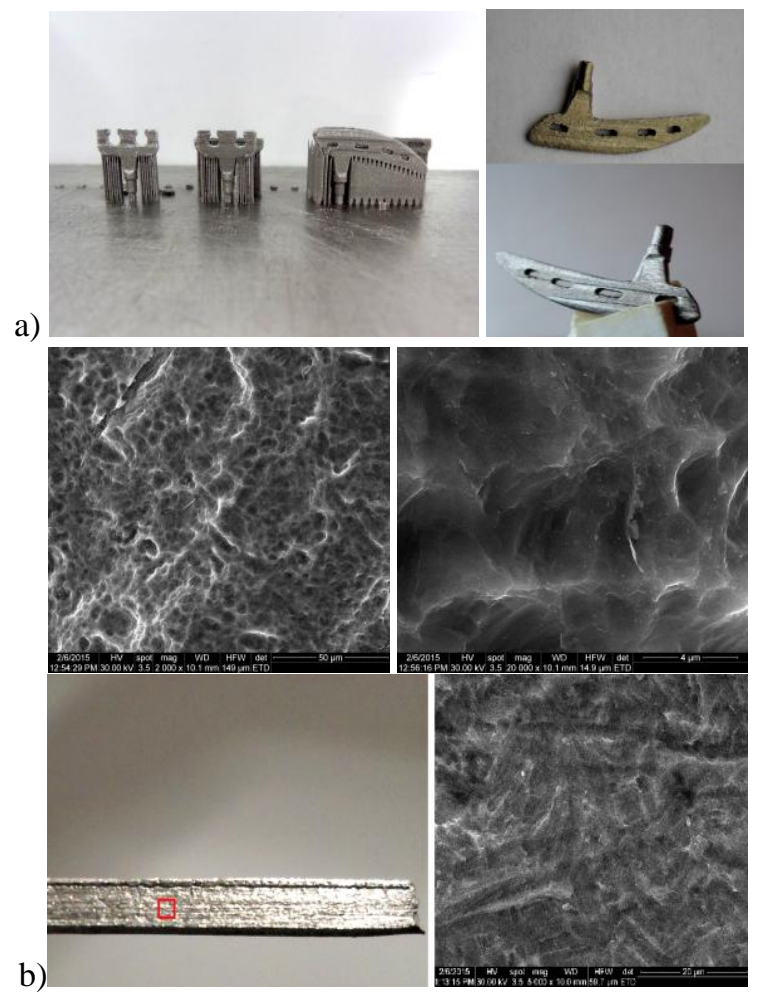

Fig. 2. a) Customized blade dental implant made by

AM after SLA process with micro pits between

1-4 $\mu \mathrm{m}$ (2000x and 20,000x magnification);

b) Rough surface of an experimental part made by AM from Ti with $\mathrm{R}_{\mathrm{a}}=4.5 \mu \mathrm{m}$ (5000x magnification)

Orthopedic roughening and dental implants utilizing alumina $\left(\mathrm{Al}_{2} \mathrm{O}_{3}\right)$ abrasives is a common practice to enhance implant osteointegration in vivo [58-60]. However, the use of apatite abrasives is often preferred as it enhances bone formation [61-63]. It has been shown that this technique can be effective in depositing a thin layer of $\mathrm{Ca}-\mathrm{P}$ on the surface being roughened [58, 63-65].

Some researchers had proved that the manufacturing process and patterned topography have a significant influence on long term adherence and cell proliferation in vitro, irrespective of composition and surface roughness [58, 66], and early controlled osteoblast alignment was demonstrated on patterned substrates [58, 67].

Recently, a novel approach CoBlast ${ }^{\mathrm{TM}}$ (Coated and Blasted) has been shown as an alternative process to deposit HA and substituted apatite's onto Ti substrates [58, 68-71]. The CoBlast technique is 
based on the convergent flow of an abrasive and a doping stream onto the implant surface which can effectively impregnate the metal with the doping material [68].

The CoBlast approach manipulates the ability of abrasive blasting to achieve surface roughening and bioactive layer deposition [58, 71]. Abrasive blasting involves impacting the implant metal surface with abrasive particles under pressure to roughen the surface.

It was also proved that employing differing grades of apatite abrasives in the CoBlast process, greater control over surface topography can be achieved, which offers the capability to improve bone-implant contact in vivo [58].

\section{Conclusions}

Advances in manufacturing, cell biology and material science have driven the development of new biological coatings for medical implants that aim to recapitulate the natural environment of growing bone [72]. In recent years, according to the modern concepts of bone tissue engineering, porous structures have been extensively investigated and different methods were developed for increasing the osteointegration of $\mathrm{Ti}$ implants via surface treatments.

This study presents a summary of the surface treatments applied on $\mathrm{Ti}$ implants like: inorganic coatings, coatings with organic biomolecules, composite coatings with $\beta$-TCP and chitosan, biomimetic coating with calcium-phosphate and collagen, and SLA process.

The studies demonstrated the potential of surface treatment applied on $\mathrm{Ti}$ implants and the biologic responses were investigated in different in vitro studies, in which human fibrin clot formation and the behavior of human osteoblasts cells were analysed. The osteointegration of implants was also tested in vivo in histological studies and satisfactory outcomes were investigated.

However, the ideal endosseous implant should be able to promote osteointegration, deter bacterial adhesion and minimize prosthetic infection. Further studies that clearly demonstrate the benefits of surface treatment on $\mathrm{Ti}$ implants are needed. A correlation between studies on surface treatments and in vivo tests would lead to a better osseointegration knowing all aspects that may influence the osteoinduction and osteoconduction.

\section{Acknowledgements}

This paper is supported by the Sectoral Operational Programme Human Resources Development POSDRU/159/1.5/S/137070 financed from the European Social Fund and by the Romanian Government. This paper was also supported by the PN-II-PT-PCCA-2013-4-0917, project no. $115 / 2014$.

\section{References}

* e-mail: sorin.cosma@tcm.utcluj.ro

[1]. D.F. Williams, Biomaterials, 29, 2941-2953 (2008).

[2]. M.N. Helmus, D. F. Gibbons and D. Cebon, Toxicologic Pathology, 36, 70-80 (2008).

[3]. L. L. Hench, J. R. Jones and P. Sepulveda, Future Strategies for Tissue and Organ Replacement, Imperial College Press, 3-24, London (2002).

[4]. R. Beutner, J. Michael, B. Schwenzer and D. Scharnweber, J. R. Soc. Interface, 7 (Suppl. 1), S93-S105 (2010).

[5]. P.D. Constantino and C.D. Friedman, Otolaryngol. Clin. North Am., 27, 1037-1073 (1994).

[6]. S. Tugulu, K. Lowe, D. Schamweber and F. Scholtting, J Mater Sci Mater Med, 21, 27512763 (2010).

[7]. M.M. Hossain and W. Gao, Trends Biomater. Artif. Organs, 22(3), 144-157 (2008).

[8]. P.H. Chua, K.G. Neoh, E.T. Kang and W. Wang, Biomaterials, 29, 1412- 1421(2008).

[9]. L. Xie, X. Liao, G. Yin, Z. Huang, D. Yan, Y. Yao, W. Liu, X. Chen and J. Gu, J. Biomed. Mater. Res,. 98A (Part A), 312-320 (2011).

[10]. Y. Fan, K. Duan and R. Wang, Biomaterials 26(14), 1623-1632 (2005).

[11]. H. S. Kim, Y. Yang, J.T. Koh, K.K. Lee, D.J. Lee, K.M. Lee and S.W. Park, J Biomed Mater Res B Appl Biomater, 88B, 427-435, (2009).

[12] C. O’Sullivan, P. O’Hare, G. Byme, L. O’Neill, K.B. Ryan and A.M. Crean, Coatings, 1, 53-71 (2011).

[13]. K. Kuroda and M. Okido, Bioinorganic Chemistry and Applications, 2012, 1-7 (2012). 
[14]. C. Aparicio, D. Rodriguez and F.J. Gil, Materials Science and Engineering, C 31, 320324 (2011).

[15]. C.T. Kwok, P.K. Wong, F. Cheng and H.C. Man, Applied Surface Science, 255(13) 67366744 (2009).

[16]. E. Alpaslan, B. Ercan and T. J. Webster, Int J Nanomedicine, 6, 219-225 (2011).

[17]. S. Sobieszczyk and R. Klotzle, Advances in Materials Sciences, 11(1), 17-26 (2011).

[18]. X.F. Xiao, R.F. Liu and T. Tian, Materials Science-Poland, 27, No. 1, 23-31 (2009).

[19]. W. S. Medeiros, M. V. Oliveira, L. C. Pereira, and M. C. Andrade, Artificial Organs, 32(4) 277-282 (2008).

[20]. L. T. Jonge, S. C. Leeuwenburgh, J. G. Wolke, and J. A. Jansen, Pharmaceutical Research, 25(10), 2357-2369 (2008).

[21]. R. Milner and I. L. Campbell, J. Neurosci. Res., 69(3), 286-291 (2002).

[22]. J.J. Van Den Beucken, J.J. Walboomers, S.C.G. Leeuwenburgh, M.R.J. Vos, N.A.J.M. Sommerdijk, R.J.M. Nolte and J.A. Jansen, Acta Biomater, 3 (4), 587-596 (2007).

[23]. S. Lee and H. Shin, Advanced Drug Delivery Reviews, 59 (4-5), 339-359 (2007).

[24]. J. Wang, J. Guo, J. Liu, L. Wei, G. Wu, Int. J. Mol. Sci., 15 (6), 10150-10168 (2014).

[25]. K. Muller, Molecular Phylogenetics and Evolution, 31(2), 780-782 (2004).

[26]. Y. Liu, R.O. Huse, K. Groot, D. Buser, and E.B. Hunziker, Journal of Dental Research, 86(1), 84-89 (2007).

[27]. A.D. Peye, D.E.A. Lockhart, M.P. Dawson, C.A. Murray and A.J. Smith, J. Hosp. Infect, 72(2), 104-110 (2009).

[28]. M. Kazemzadeh-Tarbat, J. Kindrachuk, K. Duan, H. Jenssen, R. E. W. Hancock, and R. Wang, Biomaterials, 31(36), 9519-9526 (2010).

[30]. G. Bajaj, W.G. Van Alstine and Y. Yeo, Plos One, 7(1), e30899 (2012).

[31]. M. Lee, W. Li, R. K. Siu, J. Whang, X. Zhang, C. Soo, K. Ting, and B. M. Wu, Biomaterials, 30(30), 6094-6101 (2009).

[32]. A.K. Singla, M. Chawla, J Pharm Pharmacol, 53(8), 1047-1067 (2001).
[33]. R.A.A. Muzzarelli, M. Mattioli-Belmonte, A. Pugnaloni and G. Giagini, Chitin and Chitinases, 251-264 (1999).

[34]. V. Hamilton, Y. Yuan, D.A. Rigney, A.D. Puckett, J.L. Ong, Y. Yang, S.H. Elder and D. Bumgardner, J Mater Sci Mater Med, 17(12): 1373-1381 (2006).

[35]. L.J.R. Foster, K. Thomson, H. Marcal, J. Butt, S.L. Watson and D. Wakefield, Biomacromolecules, 11(12), 3563-3570 (2010).

[36]. P. Renoud, B. Toury, S. Benayoun, G. Attik and B. Grosgogeat, Plos One, 7(7), e39367 (2012)

[37]. X. Li, X.Y. Ma, Y.F. Feng, Z.S. Ma, J. Wang, T.C. Ma, W. Qi, W. Lei and L.Wang, Biomaterials, 36, 44-54 (2015).

[38]. M.G. Raucci, V. Guarino, L. Ambrosio, J. Funct. Biomater, 3 (4), 688-705 (2012).

[39]. W.J. Grzesik, P.G. Robey, J. Bone Miner. Res., 9 (4), 487-496 (1994).

[40]. H.Y. Cheung, K.T. Lau, T.P. Lu, D. Hui, Compos. Part B: Engineering, 38(3), 291-300, (2007).

[41]. Z. Xia, X. Yu, M. Wei, J. Biomed Mater Res. Part B: Applied Biomaterials, 100B (3), 871881 (2011).

[42]. S. C. Cosma, N. Balc, D. Leordean, S. Matei, International Virtual Research Conference In Technical Disciplines, Slovakia, pp. 18-23 (2014).

[43]. W. Att, N. Hori, F. Iwasa, M. Yamada, T. Ueno and T. Ogawa, Biomaterials, 30(26), 4268-4276 (2009).

[44]. H. Aita, N. Hori, M. Takeuchi, T. Suzuky, M. Yamada, M. Anpo and T. Ogawa, Biomaterials, 30(6), 1015-1025 (2009).

[45]. R. Adell, B. Eriksson, U. Lekholm, P.I. Branemark, T. Jemt, Int J Oral Maxillofac Implants, 5(4), 347-59, Winter (1990).

[46]. H.P. Weber, C.C. Crohin, J.P. Fiorellini, Clinical Oral Implants Research, 11(2), 144153 (2000).

[47]. R. Mericske-Stern, T. Steinlin-Schaffner, P. Marti and A. Geering, Clinical Oral Implants Research, 5(1), 9-18 (1994).

[48]. G.A. Zarb, A. Schmitt, Journal of Prosthetic Dentistry, 63(4), 451-457 (1990). 
[49]. R. Mericske-Stern, M. Oetterli, P. Kiener, E. Mericske, International Journal of Oral and Maxillofacial Implants, 17(5), 678-686, (2002).

[50]. D. Buser, R. Mericske-Stern, K. Dula, N. Lang, Advances in Dental Research, 13(1), 153-161 (1999).

[51]. D. Buser, Proceedings of the 3rd European Workshop on Periodontology: Implant Dentistry, Session A: Surface, 88-101, Berlin (1999).

[52]. A. Behneke, N. Behneke, B. d'Hoedt, Int. J Oral Maxillofac Implants, 15 (5), 633645(2000).

[53]. A. Behneke, N. Behneke, B. d'Hoedt, Int. J Oral Maxillofac Implants, 17 (6), 799-810 (2002).

[54]. M. Bornstein, P. Valderrama, A. Jones, T.G. Wilson, R. Seibl and D.L. Cochran, Clin Oral Implants Res., 19(3), 233-241 (2008).

[55]. A. Wennerberg, T. Albrektsson, Int. J. Oral Maxillofac, Implants, 15, 331-344 (2000).

[56]. G. Juodzbalys, M. Sapragoniene, A. Wennerberg, Stomatologija, Baltic Dental and Maxillofacial Journal, 5, 101-105, (2003).

[57]. T. Albrektsson, L. Sennerby and A. Wennerberg, Periodontology 2000, 47 (1), 1526 (2008).

[58]. C. O’Sullivan, P. O’Hare, G. Byrne, L. O'Neill, K. B. Ryan, and A. M. Crean, Coatings, 1 (1), 53-71 (2011).

[59]. A. Wennerberg, A. Ektessabi, T. Albrektsson, C. Johansson, B. Andersson, Int. J. Oral Maxillofac Implants, 12 (4), 486-494 (1997).

[60]. A. Abron, M. Hopfensperger, J. Thompson, L.F. Cooper, J. Prosthet. Dent., 85(1), 40-46, (2001).
[61]. K. Ishikawa, Y. Ueyama, T. Mano, K. Suzuki, T. Matsumura, Processing and Fabrication of Advanced Materials VIII, (2001).

[62]. H. Nakada, T. Sakae, R. Legeros,J.P. Legeros, T. Suwa, Y. Numata, K. Kobayashi, Implant Dent., 16 (3), 281-289, (2007).

[63]. T. Mano, Y. Ueyama, K. Ishikawa, T. Matsumura, K. Suzuki, Biomaterials, 23 (9), 1931-1926, (2002).

[64]. U. Gbureck, A. Masten, J. Probst, R. Thull, Mater. Sci. Eng: C, 23 (3), 461-465, (2003).

[65]. K. Ishikawa, Y. Miyamoto, M. Nagayama, K..J. Asaoka, Biomed. Mater. Res., 38(2), 129134, (1997).

[66]. M. Bigerelle, K.J. Anselme, Biomed. Mater. Res. Part A, 75A (3), 530-540, (2005).

[67]. A. Puckett, R. Pareta, T.J. Webster, Inter. J. Nanomed., 3(2), 229-241, (2008).

[68]. R. Mericske-Stern, M. Oetterli, P. Kiener, E. Mericske, Int. Journal Oral Maxillofacial Implants, 17 (5), 678-686 (2002).

[69]. L. O’Neill, C. O'Sullivan, P. O'Hare, P. Sexton, L. Keady, F. O'Donoghue, J. Surf. Coat. Technol., 204 (4), 484-488 (2009).

[70]. C. O'Sullivan, P. O'Hare, N.D. O'Leary, A.M. Crean, K. Ryan, A.D. Dobson, L. O'Neill, Biomed. Mater. Res. Part B: Applied Biomaterials, 95B (1), 141-149 (2010).

[71]. P. O'Hare, B. Meenan, A. George, G. Byrne, D. Dowling, J. Hunt, Biomaterials, 31 (3), 515522 (2010).

[72]. B. Zhang, D. Myers, G. Wallace, M. Brandt, P. Choong, International Journal of Molecular Sciences, 15(7), 11878-11921 (2014).

Received: 29 April 2015 Received in revised form: 7 June 2015 Accepted: 8 June 2015 